\title{
Governance and Performance: The Performance of Dutch Hospitals Explained by Governance Characteristics
}

\author{
Jos L. T. Blank • Bart Laurents van Hulst
}

Received: 30 July 2009 / Accepted: 25 January 2010 / Published online: 24 February 2010

(C) The Author(s) 2010. This article is published with open access at Springerlink.com

\begin{abstract}
This paper describes the efficiency of Dutch hospitals using the Data Envelopment Analysis (DEA) method with bootstrapping. In particular, the analysis focuses on accounting for cost inefficiency measures on the part of hospital corporate governance. We use bootstrap techniques, as introduced by Simar and Wilson (J. Econom. 136(1):31$64,2007)$, in order to obtain more efficient estimates of the effects of governance on the efficiency. The results show that part of the cost efficiency can be explained with governance. In particular we find that a higher remuneration of the board as well as a higher remuneration of the supervisory board does not implicate better performance.
\end{abstract}

Keywords DEA · Bootstrapping · Hospitals · Governance

\section{Introduction}

Developments in health care policy in western countries during the last two decades have been characterised by liberalising markets, financial reforms and deregulation. Many health care systems are being transformed from centrally governed systems into regulated competitive markets (see e.g. [7, 16, 18, 24, 30]). Although there is a large variety of systems from country to country, there are some common characteristics. Generally, there has been a shift in competencies from ministries and central authorities to health care suppliers and insurers with regard to service price setting, capacity planning, investments, business conduct, strategic decisions and property rights. The impact

J. L. T. Blank • B. L. van Hulst $(\bowtie)$

Institute for Public Sector Efficiency Studies, TU Delft,

P.O. Box 5015, 2600 GA Delft, The Netherlands

e-mail: b.l.vanhulst@tudelft.nl of these changes has been analysed extensively. Most of this research is focused on issues concerning the relation between the characteristics of suppliers, on the one hand, (issues such as scale, scope, property rights and market concentration) and efficiency and quality on the other hand. The policy reforms were, however, accompanied by substantial change to the way suppliers were managed and controlled. Whereas previously a single, uniform management and control model was used, now a variety of models have been established. Large variations were developed in the size of the management board, the size of the supervisory boards, the remuneration of board members, the intensity of the supervisory board's control, the application of integrity codes and the transparency of decision-making. So far researchers have not paid much attention to these aspects of management and control, which can be summarised in the term 'corporate governance', or to their quantitative effects on productivity and efficiency. Although literature on this issue is scarce, some interesting approaches can be found (see e.g. [1, 6, 8, 9, 12]). This article therefore focuses on the relationship between corporate governance and efficiency.

An interesting case is the Dutch hospital industry, where the corporate governance is embedded in a governance code. A governance code provides guidelines for good governance, adequate supervision, accountability and justification and is an instrument for self-regulation. The urge to have guidelines for good governance has arisen as there is less supervision from the government. A governance code fills the gap of deregulation. The practice of governance codes in the Dutch hospital industry started a decade ago. In 1999 the Health Care Governance commission published recommendations and guidelines for good governance. The recommendations gave momentum to the debate over good governance and supervision. This resulted in several 
different governance codes in the Dutch health care system. This situation lasted until 2005, when a single governance code was developed for almost the entire health care system. The academic hospitals, due to regulation, have their own specific governance code.

Summarizing, most of the research on the impact of health care reforms directly focuses on the relationships between the main aspects of reform, such as non-regulated prices, free market entry and competition, and on the efficiency of health care providers. No attention is paid to more indirect effects through changes in corporate governance due to the reform. To our knowledge no research has been carried out yet on the effects of corporate governance structures on efficiency in a health care industry. Since large variation exists in corporate governance structures and relevant data are available, the Dutch hospital industry provides a unique case to establish this type of relationships.

In this paper we quantify the effects of corporate governance structure on efficiency of Dutch hospitals. To do so, we apply Data Envelopment Analysis (DEA) to derive cost-efficiency scores and follow up by a second stage of the analysis. Bootstrapping techniques are applied to deal with consistency and bias-correction (see [28]). The effect (if any) of corporate governance structure factors on the cost-efficiency scores is identified. We apply this approach to a set of Dutch hospital data since we wish to provide Dutch hospitals with relevant information on establishing productive corporate governance structures. Earlier work on the efficiency of Dutch hospitals can be found in Blank and Valdmanis (see [3]), Blank and van Hulst [5] and Blank and Merkies [4].

A two-stage analysis that assesses the impact of explanatory factors on efficiency scores derived using data envelopment analysis (DEA) has garnered attention in the literature. Whereas some have used Ordinary Least Squares (OLS), Tobit analysis has been the most popular analytical method. In this method the output-based or the reciprocal of the input-based efficiency score is regressed on a variety of variables thought to affect efficiency (see e.g. [17]). Simar and Wilson [28] challenge this approach by demonstrating that in the second stage:

- Serial correlation arises and explanatory variables are correlated with error terms, which disappear at a slow rate of convergence;

- The efficiency score, which is the dependent variable in the second stage, has a bias.

As an alternative to simply using the efficiency measure as a discrete point with a bias, Simar and Wilson [28] advocate the use of bootstrapping techniques in order to obtain unbiased and consistent estimates. Various studies have recently applied interesting applications of the Simar and Wilson technique to hospital data (see e.g. [21, 22, 29]).
The outline of this paper is as follows: "Economic theory on corporate governance" describes economic theory on corporate governance; in "Model and method" we define the DEA model and the bootstrapping procedure; in "Data" the available data is described; in "Empirical results" we present the empirical results and conclude the paper in "Conclusions".

\section{Economic theory on corporate governance}

There is no general economic framework for evaluating corporate governance structure and the efficiency of business entities. Some elements refer directly to the principal agent problem, which reflect the differing goals of various stakeholders. Government wants to maximise public values, whereas members of the management board or the supervisory board strive to maximise individual goals, such as remuneration or status. In the case of hospitals, patients want to maximise accessibility and quality of care. The extent to which each stakeholder succeeds in achieving these goals strongly depends on their relative position with regard to information, market power, and the instruments available to influence the outcomes of the business process (institutional context). It also depends on the personal characteristics of stakeholders (quality, experience and ethics). Consequently, theory on corporate governance includes aspects of agency theory, production theory, industrial economics and institutional economics. With particular respect to agency theory, Bozec and Dia [6] present an interesting overview.

We present a rather heuristic theoretical approach in discussing various characteristics of corporate governance structure. We distinguish four major clusters of characteristics: the management board, the supervisory board, the external stakeholders and a cluster of institutional relationships between various stakeholders.

\section{Management board}

The management board can be regarded as a resource in the production process. Due to the production structure, size and quality should be in accordance with the level and composition of the services and goods provided. Deviations from the optimal level of management are considered to be allocative efficiencies. For example, Rodríguez-Álvarez and Lovell [23] present an application to the Spanish public hospital sector and observe persistent allocative inefficiency in variable inputs and overcapitalisation in these hospitals. A focus on the continuing improvement of employee skills through training and education is also seen as part of the quality of management (see e.g. [1]). Evidence for the hypothesis that board size and efficiency are negatively 
correlated can be found in Eisenberg et al. [11] and Yermack [32]. The size of the board can be measured as the number of board members, whereas quality can be measured by the members' level of education, the number of years of board experience and the number of new board members. The composition of the board in terms of profession (e.g. economist, lawyer or doctor) may also reflect management board quality. A rather indirect measure of quality is remuneration.

\section{Supervisory board}

The supervisory board's main assignment is to act as a countervailing power to the management board. The supervisory board audits and advises the management board. Based on legislative instruments they approve the annual accounts and budgets, monitor the integrity of the hospital and have a say in strategic decisions (such as mergers). Their activities can also be regarded as part of a production process, in which resources are transformed into a number of audits, checks and advice. The size of the board and the quality of its members are therefore relevant characteristics. One should bear in mind that board members may also have personal preferences that conflict with public goals. Personal characteristics of the board may therefore also reflect the ability to accomplish these personal preferences. To accurately reflect the supervisory board's size and quality, the same type of variables used for the management board should be included.

\section{Other stakeholders}

Other stakeholders include the central government, insurance companies and patients. It is obvious that central and local governments dictate the regulatory environment, which consequently determines the playing field for commercial enterprises. Issues such as capacity planning, price setting, budget allocation, profit/not-for-profit and so forth also affect the corporate governance structure. Interesting examples of research on the effects of ownership and profit/not-for-profit entities on efficiency can be found in Diboky and Ubl [8] (also with bootstrapping techniques) and Mutter and Rosko [19] (US hospitals). Since these issues are not a part of our research, we will exclude them from further discussion.

Since insurance companies are hospitals' major clients they have a certain influence on the corporate governance structure. The way in which insurance companies are able to use their influence, and the degree to which they do, differs not only according to the regulatory environment but can also differ across organisations: compare, for instance, a HMO and a for-profit hospital. In the Dutch case insurance companies and hospitals are strictly independent, however through their regional market power insurance companies have informal influence on corporate governance.

The role of patients in the corporate governance structure will be expressed in the way patients are able to affect business conduct. Some firms, for instance, provide client (patient) representation on a statutory basis.

\section{Multi-actor dependencies}

Multi-actor dependencies refer to the formal and informal relationships between various actors. The relationship between the management board and the supervisory board is one example. We can distinguish two types of relation; first the management board with final responsibility and second the supervisory board or management subordinated by a board of governors of the foundation. In case of a supervisory board the management board has a maximum of competence power and will be executive. In case of a board of governors the board of governors has less competence power and will determine the policy, management has the role of the executive.

Another relevant factor is board independence. Outside managers are supposed to fulfil their monitoring function better than executive managers because they are concerned about their reputation (see e.g. [14]). Baysinger and Hoskisson [2], on the other hand, claim that inside managers have inside information and are therefore in a better position to evaluate business conduct and performance. Another aspect affecting boards is internal relations: a board might have a chairperson but it is also possible to have a collegial board. Finally the members of the board can be either internal, in case they are employees of the hospital, or external, i.e. an external interim manager.

\section{Model and method}

As mentioned in the introduction, we have applied a twostage estimation procedure with bootstrapping to investigate the effect of governance variables on hospital performance. We followed the methodology indicated as algorithm 1 in Simar and Wilson ([28, page 41-42]), the methodology of algorithm 1 is described in this chapter. The first stage of the procedure is to estimate the cost efficiency of hospitals. The second stage consists of explaining cost efficiency with governance variables. In the second stage a bootstrap procedure is applied. The second stage bootstrap procedure leads to more accurate estimators for the explanatory variables.

In the first step of our analysis, we conducted standard cost efficiency DEA as described by Färe et al. [15], for on overview of DEA literature see [13]. Since we have information on input prices for our sample of Dutch hospitals, we used the cost-efficiency model rather than the technical-efficiency DEA model that does not require 
input prices. In this standard cost-efficiency DEA model the cost efficiency of hospital ' $\mathrm{A}$ ' equals the ratio of minimum cost to actual cost. In other words, we gauge the minimum expenditure required to produce service levels given resource prices. The actual cost efficiency measure (CE) is derived by the radial distance between the observed hospital's resources-services correspondence to the 'best practice' frontier. This best practice frontier is constructed by the linear combination of hospitals producing the same levels of services as hospital A but at a lower level of cost.

The mathematical formulation is:

$$
C E=\min _{z, x} \frac{w^{A} x^{A}}{w^{A} x} \quad \text { subject to }
$$

$\sum_{j} z^{j} y^{j} \geq y^{A}$

$\sum_{j}^{j} z^{j} x^{j} \leq x^{A}$

$z^{j} \geq 0$

and $\quad \sum_{j} z^{j}=1 \quad($ in case of $V R S)$

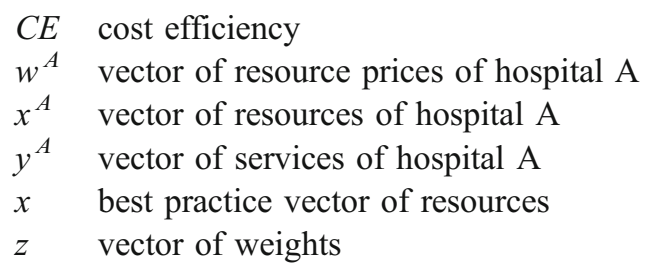

The model described here assumes constant returns to scale (CRS). CRS has been justified as long-term equilibrium, since a hospital can adjust its size over time. However, it makes sense to correlate some of the explanatory variables with the size of the hospital, e.g. remuneration of the board and size of the board. If we assume CRS, this could lead to conclusions about the governance variables, which are ambiguous. This is because the estimated parameters also tell us something about the relation between size and efficiency and whether the assumption of CRS is valid. Variable returns to scale (VRS) deals with scale effects. In general it is easier to be cost efficient under VRS then under CRS. Instead of choosing between CRS and VRS we applied both and discussed the results (e.g. [31]). In the model VRS means that we have to add the restriction that the sum of $z^{j}$ equals one.

After solving for the cost-efficiency scores for hospitals in our data set, we regressed the reciprocal of the costefficiency scores on a set of explanatory variables. Our cost-efficiency scores are obtained as results which theoretically ranges from zero to one, so the reciprocal varies from one to infinity. We do so because we want to apply a truncated regression. A higher reciprocal therefore implies greater cost inefficiencies. The (explanatory) variables account for the governance variables for each hospital. The regression equation is given by:

$\delta=\beta_{0}+\sum_{k} \beta_{k} Q_{k}+\varepsilon \geq 1$

$\delta \quad$ reciprocal of the cost efficiency score

$Q_{k} \quad$ k-th environmental feature

$\beta_{k} \quad$ parameters to be estimated

$\varepsilon \quad$ error term

However, note that $\delta$ is unobserved and is replaced by the estimates $\hat{\delta}$. So the actual equation is given by:

$\hat{\delta}=\beta_{0}+\sum_{k} \beta_{k} Q_{k}+\varepsilon \geq 1$

There are several methods to estimate (3), including OLS, Tobit analysis and truncated regression. However Simar and Wilson [28] show that there are some issues in estimating Eq. 3. First, the estimates of the cost-efficiency scores have bias. Second, because the cost-efficiency scores measured by the DEA approach are measured nonparametrically, there is no error term associated with the measure which when used as a dependent variable in the second stage analysis could lead to inconsistent estimators.

To address the bias of $\hat{\delta}$ we begin by specifying the equation given in (3):

$\hat{\delta}=E(\hat{\delta})+u$

with $E(u)=0$. The bias of the estimator $\hat{\delta}$ is defined by:

$\operatorname{bias}(\hat{\delta}) \equiv E(\hat{\delta})-\delta$

Substituting (2) and (4) and rearranging terms yields:

$\hat{\delta}-\operatorname{bias}(\hat{\delta})-u=\beta_{0}+\sum_{k} \beta_{k} Q_{k}+\varepsilon \geq 1$

Even though the $u$ 's have a zero mean, the term $\operatorname{bias}(\hat{\delta})$ does not, it is always strictly negative in finite samples. Although the $u$ 's are unknown and cannot be estimated, the bias term can be estimated by bootstrap methods (for a detailed discussion of the bootstrapping approach, see Efron and Tibshirani [10] and Simar and Wilson [27]). The bootstrap estimates of the bias can be used to obtain a bias-corrected estimator of $\delta$ :

$\hat{\hat{\delta}}=\hat{\delta}+\operatorname{bia} \hat{a}(\hat{\delta})$

Next we address the consistency of the estimators. As we have already noted $\delta$ is unobserved and is replaced by 
the estimates $\hat{\delta}$. However $\hat{\delta}$ has a serial correlation, because $\hat{\delta}$ depends on all the observations of $\left(\mathrm{w}^{\mathrm{A}} \mathrm{x}^{\mathrm{A}}, \mathrm{y}^{\mathrm{A}}\right)$, Furthermore, the explanatory variables are correlated with $\hat{\delta}$, otherwise there would be no reason for a second stage. Asymptomatically the serial correlation and the correlation between explanatory variables and error terms disappears, but at a slow rate. This means that a maximum likelihood of $\beta$ is consistent, however the usual parametric rate of convergence $(1 / \sqrt{ } \mathrm{n})$ does not apply. Therefore using a bootstrap procedure in the second stage may be more appropriate than a simple multiple regression approach since a benefit of bootstrapping is that it leads to consistent estimates of $\beta_{k}$.

We next describe the bootstrapping procedure used in this paper. We use the algorithm indicated as algorithm 1 in Simar and Wilson [28]. Basically, the algorithm consists of a procedure in which estimates of $\delta$ are obtained and a bootstrap procedure in which estimates of $\beta_{k}$ are obtained through truncated regression:

1. Compute the DEA scores using (1) to obtain $\hat{\delta} i$.

2. Use maximum likelihood to obtain estimates $\hat{\beta}_{k}$ and $\hat{\sigma}_{\varepsilon}$ for the truncated regression of the efficiency scores on the governance variables using (3), use only the observation for which $\hat{\delta}>1$.

3. Apply the next three steps $L$ times to obtain a set of bootstrap estimates $\left\{\left(\hat{\beta}^{*}, \hat{\sigma}_{\varepsilon}^{*}\right)_{b}\right\}_{b=1}^{L}$.

3.1 For each draw $i=1, . ., \mathrm{n}$ draw $\varepsilon_{i}$ from the $N\left(0, \hat{\sigma}_{\varepsilon}\right)$ distribution with left truncation at $1-\hat{\beta}_{0}-\sum \hat{\beta}_{k} z_{k}$.

3.2 For each $i \stackrel{k}{=} 1, \ldots$, n compute $\delta_{i}^{*}=\hat{\beta_{0}}+\sum_{k} \hat{\beta_{k}} z_{k}+\varepsilon_{i}$.

3.3 Use maximum likelihood to estimate the truncated regression of $\delta_{i}^{*}$ on the $z_{k}$ 's yielding estimates $\left(\hat{\beta}^{*}, \hat{\sigma}_{\varepsilon}^{*}\right)$.

4. Use the bootstrap values as described by Simar and Wilson [28] and the original parameter estimates to construct estimated confidence intervals for each element as follows: If the distribution of $\left(\hat{\beta}_{j}-\beta_{j}\right)$ were known, the confidence interval follows from finding values $a_{\alpha}$ and $b_{\alpha}$ such that:

$\operatorname{Pr}\left[-b_{\alpha} \leq\left(\hat{\beta}_{j}-\beta_{j}\right) \leq-a_{\alpha}\right]=1-\alpha$

for small values of $\alpha>0$. However, the distribution is unknown and therefore we use the j-th element of each bootstrap value instead to find values $a_{\alpha}^{*}$ and $b_{\alpha}^{*}$ such that:

$\operatorname{Pr}\left[-b_{\alpha}^{*} \leq\left(\hat{\beta}_{j}^{*}-\beta_{j}\right) \leq-a_{\alpha}^{*}\right] \approx 1-\alpha$

Finding $a_{\alpha}^{*}$ and $b_{\alpha}^{*}$ involves sorting the values $\left(\hat{\beta}_{j}^{*}-\beta_{j}\right)$ in increasing order and then deleting $\left(\frac{\alpha}{2} \times 100\right)$ percent of the elements at either end of the sorted list. After the sorted list is determined we set $-a_{\alpha}^{*}$ and $-b_{\alpha}^{*}$ equal to the endpoints of the truncated, sorted array. The estimated $(1-\alpha)$ percent confidence interval is then given by:

$\left[\hat{\beta}_{j}+a_{\alpha}^{*}, \hat{\beta}_{j}+b_{\alpha}^{*}\right]$

Note that in the procedure the parameters are bootstrapped. It is also possible to bootstrap the DEA-scores direct $[25,26]$, our focus is however on the parameters

\section{Data}

General

In this study, we used hospital data for the year 2007. Our data comes from two sources. First of all detailed information on input and outputs were obtained from the Ministry of Health, Welfare and Sport and were collected by the Institute for Health Care Management using numerous surveys, such as financial, patient and personnel surveys. Secondly, for the data on governance, we used data from the annual reports for hospitals. The annual reports are compulsory and are systematically collected by the Central Information point Healthcare Professions (CIBG). The collected data is free obtainable in a practical digital dataset. The dataset with inputs and outputs is merged with a dataset with governance variables. For the purposes of this study, observations on hospitals with missing or unreliable data and academic hospitals were excluded from the dataset. Academic (7) hospitals have a very different cost structure due to their teaching and research activities such that comparing them to general hospitals is unreliable. Our final dataset contains 75 observations. Since there were 86 hospitals in 2007 in the Netherlands, 11 hospitals are excluded. This was due to missing data, unreliable data or in one case the hospital was excluded because it is a military hospital.

Inputs and outputs

Since the main objective of hospitals is patient care, we define the services of hospitals as the number of first-time visits (i.e. the number of patients treated by physicians without an admission) and the number of discharges. Discharges have been separated into medical specialties in order to capture case-mix differences. The dataset distinguishes over 30 specialties, so for computational ease, we aggregated these medical specialties into three categories on the basis of average length of stay (LOS) of a specialty and whether or not patients had surgery. Our first group of patients were treated by a doctor in a specialty with a LOS 
less than the general LOS. Our second and third group of patients were treated by a specialty with an above-average LOS. The distinction between the second and third group is whether the patient was treated by a surgical specialty or not.

Inputs include staff and administrative personnel, nursing personnel, paramedical personnel (such as lab technicians), other personnel (including maintenance, security and cleaning), and material supplies. Material supplies include medical supplies, food and heating. Personnel and material supplies are treated as variable resources since the hospital can change these in the short term. Regarding personnel we have data on the volume in terms of fulltime equivalents as well as salary costs, input prices are obtained by dividing costs and volume. It is possible to distinguish several inputs, but as we apply DEA we wish to reduce the number of variables. Because our focus is not really on allocation of inputs in the model we reduced the number of variables by aggregating the inputs. Descriptive statistics of the variables are given in Table 1.

\section{Governance variables}

We have information about several variables that provide information on governance; information on governance is publically available through the annual accounts, which are compulsory for hospitals. "Economic theory on corporate governance" distinguishes three major clusters of characteristics, with variables that provide information about the management board, the supervisory board and a third set of variables that refers to external stakeholders. Information about the management board includes:

- the size of the board, measured with two dummy variables. One dummy for two members and one dummy for three or more members, which leaves one member as the reference group (constant term);

- remuneration of board members. Since not all members receive the same remuneration, for practical reasons we have taken the remuneration figure for the chairperson;

- the type of contract (internal or external, with external referring in most cases to interim management).

For the supervisory board our information includes:

- remuneration of board members. For practical reasons we have taken the remuneration figure for the chairperson;

Multi-actor dependencies:

- statutory changes, measured by a dummy variable if statutory changes took place in 2007. Statutory changes refer to a change of the legal form, a change in the way care is organized or a change in the competence of the internal organs.

There are some other interesting governance variables available, such as whether the board has a chairperson or the type of administration. However, they are not usable due to a lack of variation across hospitals. For instance, all general hospitals used the same particular governance code in 2007. Some other variables were tested but did not lead to significant results, i.e. number of members that left the board and the size of the supervisory board.
Table 1 Descriptive statistics, Dutch General Hospitals 2007

\begin{tabular}{lrrrr}
\hline & Mean & Std deviation & Minimum & Maximum \\
\hline Output & & & & \\
Discharges group 1 & 13.088 & 7.403 & 1.754 & 36.094 \\
Discharges group 2 & 12.741 & 6.591 & 2.152 & 32.048 \\
Discharges group 3 & 7.066 & 3.311 & 1.344 & 17.469 \\
First-time visits & 69.146 & 31.544 & 18.429 & 152.017 \\
Input prices (in euro) & & & & \\
Staff and administrative personnel & 44.730 & 4.346 & 32.907 & 62.493 \\
Nursing personnel & 47.606 & 3.120 & 39.367 & 58.872 \\
Paramedical personnel & 111.684 & 36.368 & 54.524 & 249.741 \\
Other personnel & 34.191 & 4.186 & 10.220 & 44.695 \\
Inputs (×1000 euro) & & & & \\
Staff and administrative personnel & 11.090 & 7.050 & 1.566 & 30.093 \\
Nursing personnel & 37.789 & 21.683 & 9.474 & 109.699 \\
Paramedical personnel & 8.229 & 7.174 & 0 & 45.876 \\
Other personnel & 7.449 & 4.183 & 90 & 20.053 \\
Material supplies & 38.267 & 23.666 & 8.823 & 111.894 \\
Variable cost $(\times 1000$ euro.) & 102.824 & 60.879 & 25.978 & 290.839 \\
\hline
\end{tabular}


Table 2 shows the descriptive statistics for the governance variables.

\section{Empirical results}

For the empirical results we used FEAR (DEA results) and TSP (truncated regressions and bootstrap procedure), the DEA results were also checked with Onfront. The first step of the algorithm results in DEA-scores, Table 3 presents the statistics of the DEA-scores. The table contains the results for CRS as well VRS. The lowest score is one, representing the hospitals that are efficient.

Under the CRS assumption the average efficiency is 1.28 , the maximum ranges up to 2.12 . Under the VRS assumption the average is 1.12 while the maximum is 1.82 . These outcomes are very common. Ozcan [20] summarizes the efficiency scores of a number of hospital studies. Most of these studies report scores near 90\% (meaning the reciprocal is 1.11), depending on the DEA-variant chosen, the distinct services and resources and sample. Also note that the scores under VRS are lower then CRS, this is due to the fact that scale effects are absorbed under VRS.

The efficiency scores provide an overview of the general cost efficiency in the Dutch hospital sample. The variability of performance can be explained by differences in governance. Hence we continue with regressing the efficiency score on the governance variables using the algorithm as discussed in "Model and method". Recall that we use a bootstrap procedure to generate the results, therefore we have no point estimates of the parameters. Our results are presented as the lower and upper bound of a $95 \%$ confidence interval of the estimates. Table 4 presents the results of the second stage bootstrap estimates.
The results can be interpreted as follows. A positive sign means that the variable does not lead to better performance in terms of cost efficiency; likewise a negative sign means that the variable indicates better performance in terms of cost efficiency. Furthermore we included the confidence intervals. A long confidence interval means that there is more uncertainty about the actual value of the parameter. If the borders of a confidence interval have opposite signs, it means we are not sure if there is an interrelationship between the variable and better performance in terms of cost efficiency.

From our modeling, we find some interesting differences between the results under CRS and VRS. While under CRS and VRS we find several parameters to be significant at the $5 \%$ level, the significant parameters are not always the same parameters. In fact only the remuneration of the supervisory board is significant under both assumptions. Some of the explanatory variables under CRS are not merely a measure for governance but also a measure of scale. On the other hand if we are less restrictive with our level of significance we get more significant parameters under VRS. For example if the confidence interval is $90 \%$ instead of $95 \%$ the remuneration of the board, extern board members and statutory changes are also significant under VRS.

Under CRS we find that remuneration of the board and the size of the board are significant with a positive sign. This is partly so because of the earlier mentioned correlation with the size of the hospital for these variables. However, if we are less strict with the level of significance we find that remuneration of the board is also significant under the VRS assumption. A higher remuneration of the board does not lead to better performance in terms of cost efficiency. One can suggest all kinds of explanation for this
Table 2 Descriptive statistics, Governance variables Dutch General Hospitals 2007

\begin{tabular}{lcccc}
\hline & Mean & Std deviation & Minimum & Maximum \\
\hline Included in analyses & & & & \\
Dummy, size of the board =1 & 0.28 & 0.45 & 0 & 1 \\
Dummy, size of the board = & 0.56 & 0.50 & 0 & 1 \\
Dummy, size of the board =>3 & 0.16 & 0.37 & 0 & 1 \\
Remuneration chairperson of the board & 243.127 & 94.063 & 65.934 & 644.778 \\
Dummy, external contract (int. man.) & 0.16 & 0.37 & 0 & 1 \\
Remuneration chairperson supervisory board & 8.341 & 3.965 & 2.500 & 24.000 \\
Dummy, statutory changes & 0.49 & 0.50 & 0 & 1 \\
Excluded from analyses & & & & \\
Average number of years members of the board & 4.1 & 4.3 & 0 & 25.0 \\
Dummy, member leaving the board & 0.52 & 0.78 & 0 & 4 \\
The size of the supervisory board & 6.7 & 1.7 & 4.0 & 12.0 \\
Independence of the supervisory board & 0.27 & 0.45 & 0 & 1 \\
Statutory provision of client representatives & 0.11 & 0.31 & 0 & 1 \\
Use of NVZD-code for remuneration & 0.79 & 0.41 & 0 & 1 \\
\hline
\end{tabular}


Table 3 DEA result, statistics efficiency under CRS and VRS for the Reciprocal of the Cost

\begin{tabular}{lcc}
\hline & CRS & VRS \\
\hline Mean & 1.28 & 1.12 \\
Std deviation & 0.21 & 0.13 \\
Minimum & 1.00 & 1.00 \\
Maximum & 2.12 & 1.82 \\
95\% percentile & 1.67 & 1.34 \\
\hline
\end{tabular}

varying from overambitious management to the case were the lack of performance is indentified and expensive management is hired to get back on track.

The remuneration of the supervisory board is significant with a positive sign under both CRS and VRS. This means that when the remuneration of the supervisory board increases, the performance of the hospital, in terms of cost efficiency, gets worse. This implies that remuneration of the supervisory board is not a sufficient condition for a professional supervisory board that is able to guard the performance of the hospital.

External members in the board, in most cases interim management, leads to significant estimates with a positive sign under VRS. A plausible hypothesis is that interim management has a knowledge gap about the hospital, which may result in lower performance. However, caution is required in interpreting this result, since interim management may also reflect serious organizational problems. In that case causality between interim management and efficiency should be reversed. More details, for instance about the point of time the interim manager joined the hospital or about temporarily filling-in of a regular vacancy, may shed some light on this.

The variable statutory changes is only significant under VRS and it is only the case when we are less restrictive with our confidence interval. The sign is negative meaning that a statutory change is correlated with a more efficient score.

\section{Conclusions}

This paper investigates the effect of the corporate governance structure of hospitals on cost efficiency using the method of Data Envelopment Analysis (DEA) with a bootstrapping procedure. We use the DEA measure of cost-efficiency on the hospital level. Our focus then turns to explaining variations in cost inefficiency which is due to a hospital's corporate governance.

A popular way to conduct such analysis has been a Tobit analysis wherein the efficiency score is regressed on a variety of variables thought to affect efficiency. However, in this second stage, DEA-scores are derived relative to a best practice frontier which does not have an associated error term. Without this error term, it is possible that bias may arise leading to measurement error in the dependent variable problem i.e., biased and inconsistent estimates. Simar and Wilson [28] suggest using a bootstrapping procedure in order to obtain consistent estimates.

Following this suggestion, we proceed to an analysis of a sample of Dutch hospitals using several steps. In the first stage, DEA results indicate, that on average, cost efficiency for general hospitals is 1.28 under the CRS assumption and 1.12 under the VRS assumption. The second stage shows that the cost efficiency scores can be explained by variables that measure aspects of the corporate governance of hospitals. Whether the explanatory variables are significant depends on the assumption on the returns to scale. Especially under CRS there are some governance variables, i.e. the size of the board, that are correlated with the scale and therefore also explain scale effects. Under VRS scale effects are of course absorbed.

Developments in health care policy in the last two decades in western countries have a tendency towards deregulation. As a result management and control of the health care provider has changed. Justification, transparency

Table 4 Lower and upper bound for $95 \%$ confidence intervals for the parameter estimates

\begin{tabular}{|c|c|c|c|c|c|c|}
\hline & \multicolumn{3}{|l|}{ CRS } & \multicolumn{3}{|l|}{ VRS } \\
\hline & Median & $\begin{array}{l}\text { Lower bound } \\
(\alpha=2.5 \%)\end{array}$ & $\begin{array}{l}\text { Upper bound } \\
(\alpha=97.5 \%)\end{array}$ & Median & $\begin{array}{l}\text { Lower bound } \\
(\alpha=2.5 \%)\end{array}$ & $\begin{array}{l}\text { Upper bound } \\
(\alpha=97.5 \%)\end{array}$ \\
\hline Constant & 1.185 & 0.933 & 1.282 & 1.099 & 1.041 & 1.296 \\
\hline Dummy, size of the board $=2$ & 0.020 & -0.064 & 0.103 & -0.039 & -0.103 & 0.018 \\
\hline Dummy, size of the board $>3$ & 0.141 & 0.0001 & 0.247 & -0.032 & -0.131 & 0.037 \\
\hline Remuneration chairperson of the board & 0.145 & 0.044 & 0.253 & 0.089 & -0.010 & 0.144 \\
\hline Remuneration chairperson supervisory board & 0.095 & 0.013 & 0.183 & 0.052 & 0.001 & 0.124 \\
\hline Dummy, external contract (int. man.) & -0.019 & -0.060 & 0.146 & 0.040 & 0.010 & 0.162 \\
\hline Dummy, statutory changes & -0.014 & -0.108 & 0.042 & -0.005 & -0.103 & 0.001 \\
\hline Sigma & 0.151 & 0.127 & 0.175 & 0.110 & 0.088 & 0.122 \\
\hline
\end{tabular}

Bold: significant at the $5 \%$ level 
and good governance are import elements in the deregulated environment. It is therefore surprising that in productivity analysis not too much attention has been paid to the relation between corporate governance and cost efficiency. This paper investigates this relation for the Dutch hospital industry and contributes in the discussion over good governance. It is important to note that not all differences in cost efficiency are a result of governance. However, the board and the supervisory board call the shots in an organization, quality of governance will therefore have an impact on the performance. This paper shows that the relation between governance and cost efficiency exists and how they relate. From the viewpoint of the policymaker it is therefore important to keep on monitoring the governance, keep searching for best practices and stimulate governance structures that lead to better performance.

Acknowledgements The authors wish to thank the anonymous referees whose comments have greatly improved this paper.

Open Access This article is distributed under the terms of the Creative Commons Attribution Noncommercial License which permits any noncommercial use, distribution, and reproduction in any medium, provided the original author(s) and source are credited.

\section{References}

1. Azizi, K. H., Hosseinzadeh Lotfi, F., Saati, S., and Vahidi, A., Manpower efficiency in electricity producer companies in the view of economic management; some approaches for increment of efficiency in inefficient companies by DEA. Int. J. Math. Analysis 1:229-236, 2007.

2. Baysinger, B. D., and Hoskisson, R. R., The composition of board of directors and strategic control: Effects on corporate strategy. Acad. Manag. Rev. 15:72-87, 1990.

3. Blank, J., and Valdmanis, V., Environmental factors and productivity on Dutch hospitals: A semi-parametric approach. Health Care Manage. Sci., 2009.

4. Blank, J. L. T., and Merkies, A. H. Q. M., Empirical assessment of the economic behaviour of Dutch general hospitals. Health Econ. 13(3):265-280, 2004.

5. Blank, J. L. T., and van Hulst, B. L., Productive innovations in hospitals: An empirical research on the relation between technology and productivity in the Dutch Hospital Industry. Health Econ. 18(3):665-679, 2009.

6. Bozec, R., and Dia, M., Board structure and firm technical efficiency: Evidence from Canadian state-owned enterprises. Eur. J. Oper. Res. 177(3):1734-1750, 2007.

7. Chang, H., Chang, W.-J., Das, S., and Li, S.-H., Health care regulation and the operating efficiency of hospitals: Evidence from Taiwan. J. Account. Public Policy 23(6):483-510, 2004.

8. Diboky, F., and Ubl, E., Ownership and efficiency in the German Life Insurance Market: A DEA Bootstrap Approach, 2007.

9. Ditzel, E., Štrach, P., and Pirozek, P., An inquiry into good hospital governance: A New Zealand-Czech comparison. Health Research Policy and Systems (4:2), 2006.

10. Efron, B., and Tibshirani, R. J., An introduction to the Bootstraps. Chapman and Hall, London, 1993.
11. Eisenberg, T., Sundgren, S., and Wells, M. T., Larger board size and decreasing firm value in small firms. J. Financ. Econ. 48(1): 35-54, 1998.

12. Eldenburg, L., Hermalin, B. E., Weisbach, M. S., and Wosinska, M., Governance, performance objectives and organizational form: Evidence from hospitals. J. Corp. Finance 10 (4):527-548, 2004.

13. Emrouznejad, A., Parker, B. R., and Tavares, G., Evaluation of research in efficiency and productivity: A survey and analysis of the first 30 years of scholarly literature in DEA. Socio-Econ. Plann. Sci. 42(3):151-157, 2008.

14. Fama, E. F., and Jensen, M. C., Separation of ownership and control. J. Law Econ. 26:301-349, 1983.

15. Färe, R., Grosskopf, S., and Lovell, C. A. K., Production frontiers. Cambridge University Press, Cambridge, 1994.

16. Kittelsen, S. A. C., Magnussen, J., Anthun, K. S., Häkkinen, U., Linna, M., Medin, E., et al., Hospital productivity and the Norwegian ownership reform-A Nordic comparative study. University of Oslo, Oslo, 2008.

17. Kooreman, P., Nursing home care in The Netherlands: A nonparametric efficiency analysis. J. Health Econ. 13(3):301316, 1994.

18. McKee, M., and Healy, J., Hospitals in a changing Europe. Open University Press, Buckingham, 2002.

19. Mutter, R. L., and Rosko, M. D., The impact of ownership on the cost-efficiency of U.S. hospitals. In: Blank, J. L. T., and Valdmanis, V. G. (Eds.), Evaluating hospital policy and performance: Contributions from hospital policy and productivity research, vol. 18. Elsevier, Oxford, pp. 113-138, 2008.

20. Ozcan, Y. A., Health care benchmarking and performance evaluation. Springer, New York, 2008.

21. Pilyavsky, A. I., Aaronson, W. E., Bernet, P. M., Rosko, M. D., Valdmanis, V. G., and Golubchikov, M. V., East-West: Does it make a difference to hospital efficiencies in Ukraine? Health Econ. 15(11):1173-1186, 2006.

22. Puenpatom, R. A., and Rosenman, R., Efficiency of Thai Provincial Public Hospitals during the introduction of universal health coverage using capitation. Health Care Manage. Sci. 11 (4):319-338, 2008.

23. Rodríguez-Álvarez, A., and Lovell, C. A. K., Excess capacity and expense preference behaviour in National Health Systems: An application to the Spanish public hospitals. Health Econ. 13:157169, 2004.

24. Saltman, R. B., Bankauskaite, V., and Vrangbæk, K., Decentralization in health care. Open University Press, Berkshire, 2007.

25. Simar, L., and Wilson, P. W., Sensitivity analysis of efficiency scores: How to bootstrap in nonparametric frontier models. Manag. Sci. 44(1):49-61, 1998.

26. Simar, L., and Wilson, P. W., A general methodology for bootstrapping in nonparametric frontier models. J. Appl. Stat. 27 (6):779-802, 2000.

27. Simar, L., and Wilson, P. W., Statistical inference in nonparametric frontier models: The state of the art. J. Prod. Anal. 13:49-78, 2000.

28. Simar, L., and Wilson, P. W., Estimation and inference in twostage, semi-parametric models of production processes. J. Econom. 136(1):31-64, 2007.

29. Staat, M., Efficiency of hospitals in Germany: A DEA-Bootstrap Approach. Appl. Econ. 38(19):2255-2263, 2006.

30. Walford, V., and Grant, K., Improving health efficiency. DFID Health Systems Resource Centre, London, 1998.

31. Wilson, P. W., and Carey, K., Nonparametric analysis of returns to scale in the US Hospital Industry. J. Appl. Econ. 19(4):505-524, 2004.

32. Yermack, D., Higher market valuation of companies with a small board of directors. J. Financ. Econ. 40(2):185-211, 1996. 